\title{
Chemical study of asphaltene inhibitors effects on asphaltene precipitation of an Iranian oil field
}

\author{
Afshar Ahmadbaygi ${ }^{1}$, Behrouz Bayati ${ }^{1,}$, Mohsen Mansouri $^{1}$, Hossein Rezaei ${ }^{2}$, and Masoud Riazi ${ }^{3}$ \\ ${ }^{1}$ Chemical Engineering Department, Ilam University, P.O. Box 69315/516, Ilam, Iran \\ ${ }^{2}$ Petroleum Engineering \& Development Company (PEDEC), 1598846511 Tehran, Iran \\ ${ }^{3}$ Department of Petroleum Engineering, School of Chemical and Petroleum Eng., Shiraz University, 7134851154 Shiraz, Iran
}

Received: 26 February 2019 / Accepted: 4 December 2019

\begin{abstract}
The amount of precipitated asphaltene can be considerably reduced with pretreatment of asphaltene inhibitor, in the crude oil. Efficiency of asphaltene inhibitors mainly depends on some parameters such as $\mathrm{pH}$ of the oil and the chemical structure of asphaltene inhibitors. In this paper, the amounts of asphaltene precipitation have been experimentally measured using two $n$-paraffin precipitants; $n$-heptane and $n$-hexane. The performance of the studies on the asphaltene accumulation was studied using Fourier-Transform Infrared (FTIR) Spectroscopy analysis. The onset point has been determined by three different commercial asphaltene inhibitors. The results show that when an asphaltene inhibitor is not injected into the mixture of synthetic oil/ $n$-heptane, AOP (Asphaltene Onset Point) occurs at 35 vol. $\%$ of $n$-heptane, while with addition of $3000 \mathrm{ppm}$ of asphaltene B inhibitor, AOP occurs at 60 vol. $\%$ of $n$-heptane.
\end{abstract}

\section{Introduction}

Asphaltene in heavy crude oil can cause enormous losses in flow rate due to deposition in pipelines and operational equipment as well as obstruction of wells (Berenblyum et al., 2011; Nasralla et al., 2018; Ramirez et al., 2017). Precipitation and deposition of asphaltene have become a crucial problem to almost all petroleum production, processing and transportation facilities (Afra et al., 2018; Ahmadi and Aminshahidy, 2018; Saeedi Dehaghani and Badizad, 2017; Tirjoo et al., 2019a, b). Precipitation and deposition of asphaltene would partially or completely block the pores and change the permeability of the flow paths in reservoirs. Reducing permeability leads to additional pressure drop and consequently an increase in the amount of asphaltene precipitation, and as a result, the pores of the reservoir rock are further blocked. It can also cause to completely obstruct the flow of oil from the outlet of the well (Gharbi et al., 2017; Gonzalez et al., 2017; Loureiro et al., 2015). At initial condition, the operational pressure and temperature are very high, as a result asphaltene is soluble in the mixture of heavy crude oil bitumen and tar, but upon operational conditions changes, asphaltene deposition starts and causes flow problem (Gonzalez et al., 2017). In some cases, gas injections, including injection of $\mathrm{CO}_{2}$, can disturb the chemical and thermodynamic

\footnotetext{
* Corresponding author: b. bayati@ilam.ac.ir
}

balance of crude oil and cause precipitation of asphaltene. Of course, some key factors such as solvent type sample/ precipitant ratio and contact time cannot be ignored in the analysis of the process (David Ting et al., 2013; Ebrahimi et al., 2016; Hammami et al., 2000; Hu and Guo, 2001; Shojaati et al., 2017). Keeping the operational conditions at the level similar to the initial condition is practically impossible and is very difficult and costly work, thus effectual ways should be chosen to solve the problem. Widespread research have been performed in this field, a likely way of avoiding asphaltene precipitation that has been studied and suggested is adding and using asphaltene inhibitor, i.e., stabilizer (Ebrahimi et al., 2016; Gharbi et al., 2017). Pretreatment of chemical inhibitors can prevent precipitation, and enhance product of light oil from raw material. Asphaltene precipitation in heavy crude oil and extra-heavy crude oils is a common phenomenon. Heavy and extra-heavy crude oils have high viscosity, as well as a low API gravity (Choi et al., 2016; Doryani et al., 2018; Ghloum et al., 2010; Ovalles et al., 2016). From the molecular point of view, the asphaltenes are polar aromatic compound that exist in crude oil, which also contains resin, aromatic hydrocarbons and saturated hydrocarbons (SARA) (Bahman et al., 2018; Dehaghani et al., 2018; Doryani et al., 2016; Karambeigi et al., 2016). Asphaltene molecules are soluble in alkene but insoluble in normal alkanes (Melendez-Alvarez et al., 2016; Rogel and Moir, 2017; Sayyad Amin et al., 2017; Wang and Buckley, 2001). From the macroscopic view point, the 
asphaltene is composed of polyaromatic core, which are captured by aliphatic chain (Chávez-Miyauchi et al., 2013; Javanbakht et al., 2018; Mena-Cervantes et al., 2013; Mousavi-Dehghani et al., 2004; Ramirez et al., 2017; Wiehe et al., 2005). Asphaltene has high level of sulfur, nitrogen, and heavy metals (such as $\mathrm{Ni}, \mathrm{V}, \mathrm{Fe}$ ) and the average ratio of hydrogen to carbon atom (H:C) in asphaltene is 1:1.2 (Al-Sahhaf et al., 2002; Escobedo and Mansoori, 1995; Gonzalez et al., 2017; Javanbakht et al., 2018; Lu et al., 2008). Due to aggregation of maltene molecules in solution, it is not possible to characterize the mean molecular weight of asphaltene in crude oil.

When asphaltene molecules are separated from the oil phase form a unique phase. Asphaltene which their sizes are bigger than $500 \mathrm{~nm}$ become to precipitate (Hammami et al., 2000; Ramirez et al., 2017).

It should be borne in mind that asphaltene is stable due to the presence of resin in crude oil with polar groups and less molecular weight (Al-Sahhaf et al., 2002; Escobedo and Mansoori, 1995; Lu et al., 2008; Honse et al., 2012). Thus, to reduce the amount of asphaltene deposition, it is necessary to use a surfactant that had similar compounds with resin and diverse in the polar heads and a polar tails. Most of the costs are related to the production of raw materials for inhibitors. Therefore, asphaltene inhibitor should be selected with the optimum concentration (Imanbayev et al., 2017; Mao et al., 2017; Permanyer et al., 2002; Shojaati et al., 2017; Simakov et al., 2015; Smith et al., 2008). Recently researchers have shown that asphaltene acts as a weakly hydrous binder and also as a strong receiver of hydrous bands, which shows that asphaltene is a Lewis base. Therefore, surfactants with a Lewis acidic structure can be used as an inhibitor of asphaltene precipitation (Bahman et al., 2018). Except asphaltene, other components that exist in crude oil are called maltene, which are extracted by chromatography column (Wang and Buckley, 2001). Efficiency of asphaltene inhibitors depends on the chemical structure of inhibitors and the amount of resin, aromatic and other component that exist in asphaltene inhibitors and the amount of acidity of asphaltene inhibitor. The structure of asphaltene in crude oil is also very important to be chosen the asphaltene inhibitor with the highest efficiency. In more cases, asphaltene inhibitors that contain higher amount of resin rather than other component, have a more effect on prevention of asphaltene precipitation. It should be borne in mind that the addition of inhibitors does not always have a positive effect, and even in some cases it has a neutral and possibly negative effect. Always adding high amount of inhibitor does not have high efficiency in preventing asphaltene precipitation, therefore it is necessary to determine the optimum amount of asphaltene inhibitor. Melendez-Alvarez et al. have shown that other factors such as the type and amount of solvent, the temperature and the operating pressure are the effective parameters on inhibitory performance for reducing the amount of precipitated asphaltene (Melendez- Alvarez et al., 2016).

Ghloum et al. (2010) studied the effect of different inhibitors on asphaltene precipitation for Marrat Kuwaiti reservoirs. In that research, three commercial and four non-commercial asphaltene inhibitors have been used to determine the Asphaltene Onset Point (AOP), which is the point where asphaltene in crude oil begins to precipitate, using a Solid Detection System (SDS). In this research the effects of the $\mathrm{H}: \mathrm{C}$ ratio on AOP was also studied. For a ratio of $\mathrm{H}: \mathrm{C}$ more than 0.8 , AOP increases dramatically, suggesting that there is a higher content of hydrogen and a lower amount of carbon in the crude oil, causes AOP to occur at higher volume of $n$-paraffin. The effect of different asphaltene inhibitors on the amount of asphaltene precipitated has also been studied using the screening test. The results show that in most cases, the amount of asphaltene precipitation has further decreased when inhibitor is used with the highest resin content. It should be borne in mind that, regards to the crude oil structure, asphaltene inhibitor with a higher amount of aromatic (greater polarity), works more efficiently.

In the recent years, a viscometry method has been introduced to investigate the AOP, as well as various inhibitory effects on AOP. In this regard, Saeedi Dehaghani and Badizad (2017) examined this method on crude oil extracted from Iranian oil fields. In this method, they first synthesized synthetic oil and then added different volumes of $n$-paraffin. The point where the viscosity of the mixture of synthetic oil/ $n$-paraffin system has dramatically changed is determined as the AOP. In their research, four different inhibitors have been used to postpone AOP. Their results showed that the CDEA acts more effectively than the other inhibitors to increase the AOP due to the presence of more polar groups (Saeedi Dehaghani and Badizad, 2017).

To investigate the effect of partial asphaltene phosphorexylated on the decrease of asphaltene precipitation rate, Ovalles et al. conducted research using ASTM D-6560 method (IP-143-test). The results obtained from their study indicate that asphaltene precipitation rate has significantly decreased because of the formation of Aryl-O-P and $\mathrm{P}=\mathrm{O}$ bands which is due to the addition of partial asphaltene phosphorexylated. Of course, it should be taken into account that, at temperature of $195^{\circ} \mathrm{C}$ and the asphaltene phosphorexylated concentration of $100 \mathrm{ppm}$, the percentage of reduction of asphaltene is as high as possible (percentage of reduction of asphaltene $=42 \%$ ).

In general cases, different methods such as SDS, Ultraviolet spectrometry (UV test), filtration, viscometry and IP-143 test, are used to study the effect of various inhibitors on the amount of asphaltene precipitated (Doryani et al., 2016; Gonzalez et al., 2017).

In this work, IP-143 test and the spectrometry method have been used to investigate the effect of different inhibitors on precipitated asphaltene content and using Fourier-Transform Infrared (FT-IR) Spectroscopy test and then the obtained results were analyzed. Also, due to the fact that two methods used in this study were carried out at different temperature conditions, the effect of temperature on different inhibitory activity can also be evaluated. The spectrometry method is considered as a faster and better method than other methods of studying the effect of asphaltene inhibitors. The spectrometry method was used to determine the AOP. 


\section{Experimental}

\subsection{Materials and methods}

\subsubsection{Materials}

In this research, we used a crude oil from an Iranian oil field in west of Iran, $n$-heptane and $n$-hexane $\left(\operatorname{Merc}^{\circledR}\right.$, purity of $99 \%$ ) and toluene (Merc, purity of $99 \%$ ). Three inhibitors $\mathrm{A}, \mathrm{B}$, and $\mathrm{C}$ also have been used to reduce the amount of asphaltene precipitation.

\subsubsection{Methods}

\subsubsection{Extraction of asphaltene}

The IP-143 method (Sayyad Amin et al., 2017) was applied for the determination of crude oil asphaltene content. Two $n$-paraffins and toluene were used for precipitation and purification of asphaltene, respectively. First, $2.5 \mathrm{~g}$ of crude oil weighted and mixed with $100 \mathrm{~g}$ of $n$-heptane (ratio $: \frac{40}{1}=\frac{n \text {-paraffins }}{\text { crudeoil }}$ ). The first reflux was performed for asphaltene precipitation in crude oil by the $n$-paraffins solvent in the Soxhlet extractor. The primary reflux was done for $1.5 \mathrm{~h}$, then $n$-paraffins/crude oil solution was aged overnight in dark place. In the second stage, the obtained mixture was filtered using filter paper. The asphaltene and small amount of other components were deposited on the filter paper. The second reflux has been done for separating other components that were bonded in the filter paper by adding $n$-paraffins. In the last reflux, the sliced asphaltene into the filter paper was separated by adding toluene. Finally, the asphaltene-toluene solution put under a slow stream of air to evaporate the toluene.

In this section, two kinds of normal paraffin, $n$-Hexane and $n$-Heptane have been used to study the effect of paraffin chain length on asphaltene precipitation.

\subsubsection{Synthetic oil synthesis}

Synthetic oil was prepared in order to determine AOP and investigate the effect of different asphaltene inhibitors. For this purpose, a certain amount of asphaltene was added to the toluene solvent. To obtain a uniform solution, the resulting mixture was stirred for $5 \mathrm{~h}$.

\subsubsection{Determination of $A O P$}

To determine AOP, different volumetric percentages of $n$-paraffins were added to synthetic oil. In order to completely disrupt, the synthetic oil $/ n$-paraffin mixture was centrifuged at $3000 \mathrm{rpm}$ for $15 \mathrm{~min}$.

To determine the absorbance of each sample, $1 \mathrm{cc}$ of the upper part of the mixture was removed and mixed with $10 \mathrm{cc}$ of toluene. The absorbance values were plotted as a function of $n \mathrm{C} 7$ volume fraction. The rapid deviation from linear trend in the data points corresponds to the $n \mathrm{C} 7$ volume fraction at the onset point.

\subsubsection{Asphaltene inhibitor test}

Two methods have been used to study the effect of adding different inhibitors on the asphaltene precipitation. In the first method, spectrometry was used to evaluate the effect of asphaltene inhibitor on the amount of asphaltene precipitation at different percentages of $n$-paraffin. The samples with a different ratio of the $n$-paraffin/synthetic oil were mixed at ambient temperature for $1.5 \mathrm{~h}$, then the solution was centrifuged at $3000 \mathrm{rpm}$ for $15 \mathrm{~min}$. To investigate the effect of inhibitors, a fixed amount of inhibitor was mixed with the synthetic oil $/ n$-paraffin solution, and was stirred at ambient temperature. The absorbance value for each of sample is determined at specified wavenumber using a UV spectrometer.

In the second method, the effect of adding various amounts of different inhibitors on the amount of asphaltene precipitated was investigated using the IP-143 standard test. The weighed crude oil samples were mixed with identified amounts of inhibitor, and then placed under the shaking for several minutes to complete mixing.

Then, as mentioned above, the amount of asphaltene present in crude oil was achieved by adding different volume percentage of normal paraffin as a precipitating agent and toluene as an asphaltene solvent and was refluxed several time.

\section{Characterization}

The elemental analysis of the extracted asphaltene of crude oil sample was carried out using a COSTECH-4010 model analyzer (CHNSO analyzer). FTIR (Bruker-VERTEX 70 model analyzer) was used to structural characterization of asphaltenes. UV-Vis spectrophotometry (Cary 100 model) was used to find the concentration of an asphaltene in different samples solution. Quantitative proton $\mathrm{H}$ and carbon C NMR spectroscopy analyses were performed using a Nuclear Magnetic Resonance (NMR) BRUKER spectrometer operating at $500 \mathrm{MHz}$. Chloroform was used to dissolve the extracted asphaltene sample.

\section{Results and discussion}

\subsection{Properties of asphaltene}

To determine weight percent of component that exist in asphaltene, elemental analysis were used, which obtained results from this analysis were presented in Table 1. As it can be seen, the asphaltene content in the crude oil sample has higher carbon atoms than the other ones.

The $\mathrm{H}: \mathrm{C}$ ratio of asphaltene in the crude oil sample is 0.983. Since molecular weight of $\mathrm{H}$ and $\mathrm{C}$ are 1 and 12 , respectively, and according to the weight percentages obtained from the CHNSO test, the molar ratio of $\mathrm{H}: \mathrm{C}$ is equal to 0.98294. Ghloum et al. (2010) showed that asphaltene in crude oil is more unstable if the $\mathrm{H}: \mathrm{C}$ ratio is less than 0.8 , therefore, AOP occurs in smaller amount of $n$-paraffin. In the other hand, if the $\mathrm{H}: \mathrm{C}$ ratio is more than 0.8 , more volume of $n$-paraffin is needed to observe AOP. Thus, due to the $\mathrm{H}: \mathrm{C}$ ratio of the crude oil asphaltene, it is anticipated that AOP will be appeared at a high volume of $n$-paraffin.

The complex and rich nature of this asphaltene was studied by NMR spectra. To receive a useful information, it requires systematic approach, so as to identify/quantity 
Table 1. Elemental analysis for pure asphaltene extracted from the Iranian oil field.

\begin{tabular}{lccccc}
\hline Component & N & S & H & C & Total $^{*}$ \\
\hline Weight percent & 1 & 3.14 & 6.1 & 74.47 & 84.71 \\
\hline
\end{tabular}

${ }^{*}$ Weight percent of oxygen $=100-$ weight percent of $(\mathrm{N}+\mathrm{S}+\mathrm{H}+\mathrm{S})=100-84.71=15.29 \%$.
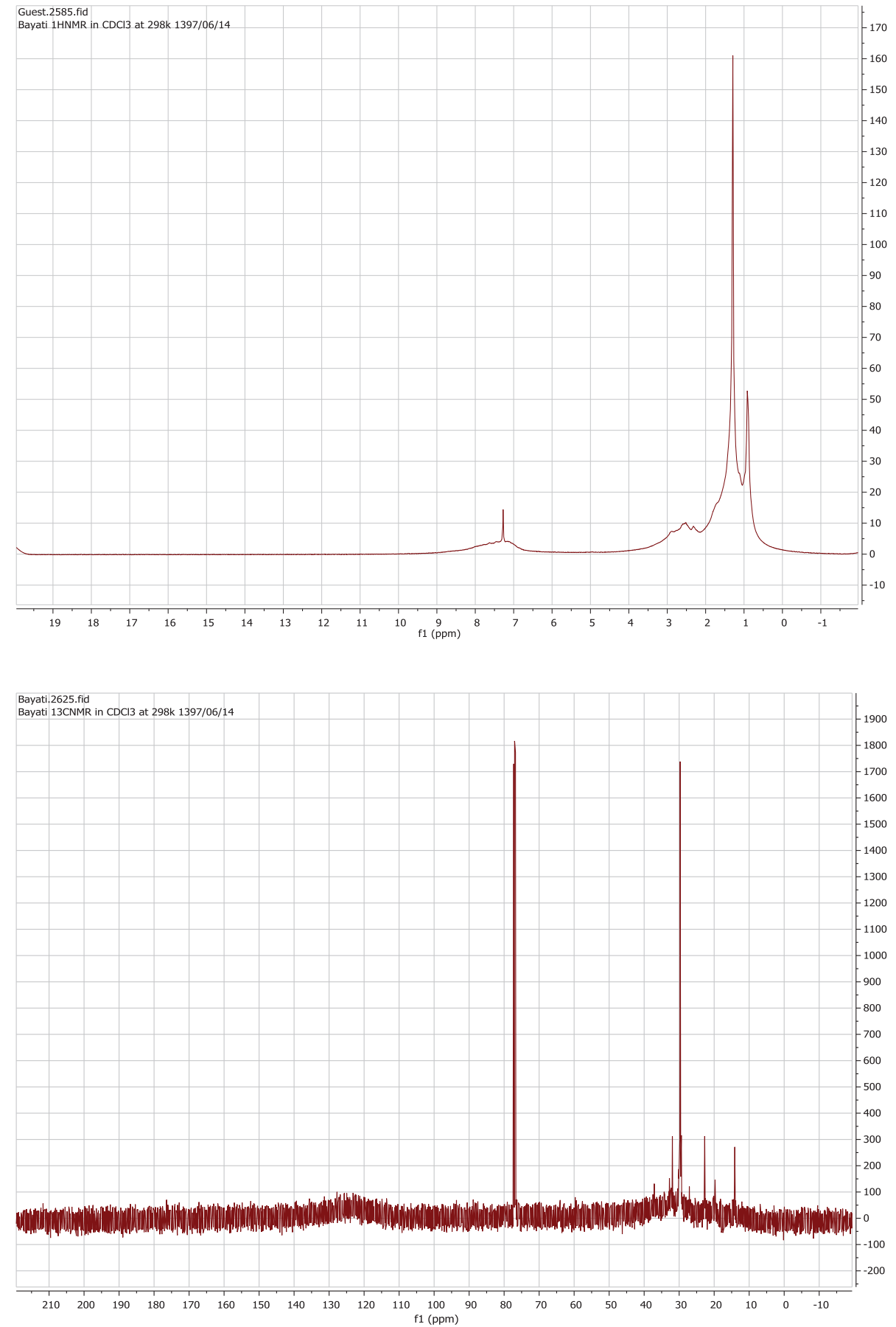

Fig. 1. NMR spectrum of the extracted asphaltene from the crude oil.

the molecular nature from these spectra. For H NMR spectra contributed by protons, the aromatic peaks are well resolved (6.5-9.5 $\mathrm{ppm})$ from the aliphatic ones
(0.5-4.5 ppm) and the spectra are more reliable. The aliphatic peaks are further divided into three types of protons ( $a, b$ and $c)$. 
Table 2. Density and $\mathrm{pH}$ of three different asphaltene inhibitors.

\begin{tabular}{lccc}
\hline Inhibitor & $\mathrm{A}$ & $\mathrm{B}$ & $\mathrm{C}$ \\
\hline Density & 0.836 & 0.976 & 0.82 \\
$\mathrm{pH}$ & 3.8 & 2.8 & 5.3 \\
\hline
\end{tabular}

The peaks at $0.5-1.0,1.0-1.85$ and $1.85-4.5 \mathrm{ppm}$ are related to $\mathrm{a}, \mathrm{b}$ and protons, respectively. These borders are approximate because the effect of hetero atoms and metals on peak shifting is neglected. Figure 1 shows the $\mathrm{H}$ NMR spectrum. It clearly shows an aromatic region and a large aliphatic domain. The aromatic:aliphatic hydrocarbon ratio is 1:7.6 and aromatic:aliphatic carbon ratio is $1: 1.7758$.

\subsection{Properties of asphaltene inhibitors}

Three different inhibitors have been used in this study. The density and $\mathrm{pH}$ of inhibitors were presented in Table 2 . As shown in Table 2, B inhibitor has a more density and acidity than other inhibitors. This inhibitor has higher acidic potency than the other two inhibitors, so it can be concluded that inhibitor B consists of greater amounts of hydrogen groups and other polar groups than both inhibitors $\mathrm{A}$ and $\mathrm{C}$. The higher the polarity of the inhibitory constituents, the greater the effect of combining the inhibitor with the polar portion of the asphaltenes, and the polarpolar bonding between the inhibitor and the asphaltenes creates a protective layer around the asphaltenes, causing non-asphaltene-induced invasion. Protect the presence of normal paraffin and prevent excessive deposition of asphaltene. Inhibitors $\mathrm{A}$ and $\mathrm{C}$ have lower acidic strength due to their constitutive structure.

FT-IR spectrum results of the asphaltene inhibitors of A, B and C, are shown in Figures 2-4, respectively.

The FT-IR spectrum of the asphaltene inhibitor A was represented in Figure 2. As shown in this figure, there is a high intensity tensile $\mathrm{N}-\mathrm{H}$ band in the wave number of $3433 \mathrm{~cm}^{-1}$, which act as a factor in creating polarity and acidity of asphaltene inhibitor A. There is a flexural N-H band in the wavenumber of $1639 \mathrm{~cm}^{-1}$, which has a similar function to tensile $\mathrm{N}-\mathrm{H}$ band. There is also a weak nonpolar band in this asphaltene inhibitor. During the wavenumber of 2854 and $2925 \mathrm{~cm}^{-1}$, C-H bands are appeared. There are non-polar bands that are related to the $\mathrm{C}=\mathrm{C}$ band at wavenumber of 1348 and $1468 \mathrm{~cm}^{-1}$.

As the FT-IR spectrum is related to asphaltene inhibitor $\mathrm{A}$, the polar bands intensity of the asphaltene inhibitor A is more severe than non-polar bands, which is due to the acidic and polarizing factor of this kind of asphaltene inhibitor (A type).

As shown in Table 2, the asphaltene inhibitor B has a density of $0.976 \mathrm{~kg} / \mathrm{m}^{3}$, indicating that the asphaltene inhibitor B has a high concentration. Therefore, in order to completely mix of this asphaltene inhibitor with the reference material (the material that should be mixed the sample to FT-IR test), asphaltene inhibitor B must be diluted with a small amount of $n$-heptane. As can be seen

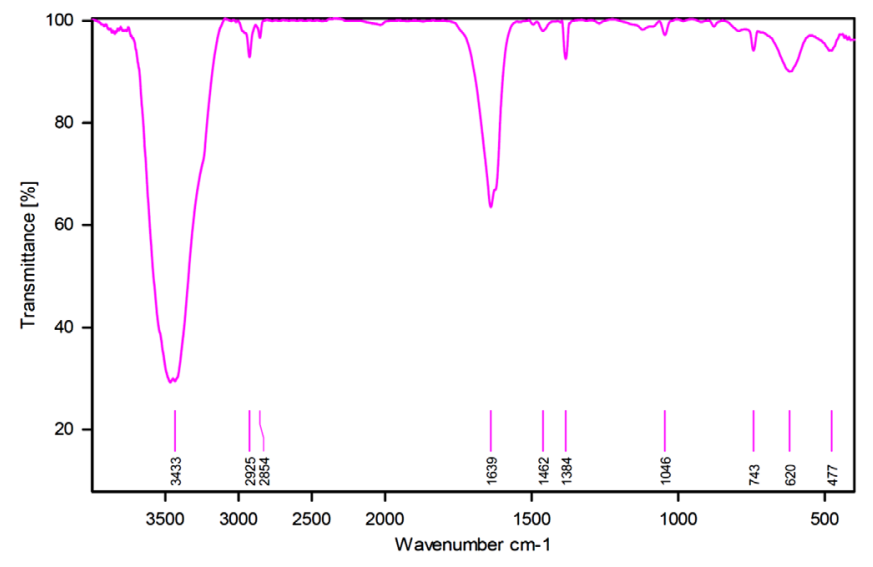

Fig. 2. The FT-IR spectrum of the asphaltene inhibitor A.

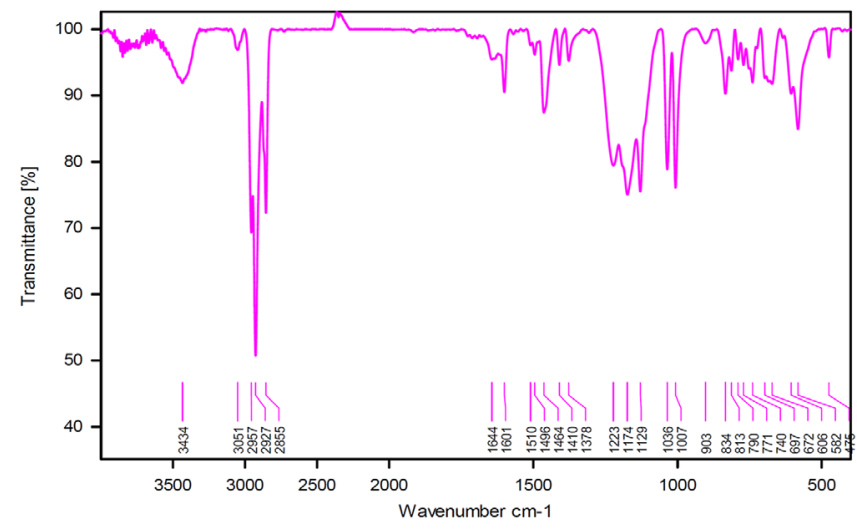

Fig. 3. The FT-IR spectrum of asphaltene inhibitor B.

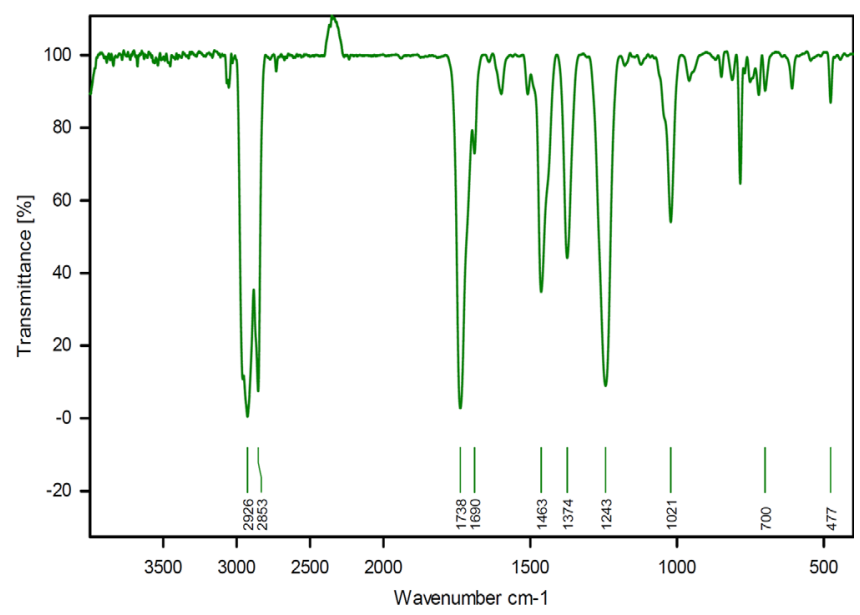

Fig. 4. The FT-IR spectrum of the asphaltene inhibitor C.

from Figure 3, the intensity of non-polar bands in the asphaltene inhibitor B is high. It can be due to the mixing of this inhibitor with $n$-heptane and the presence of nonpolar bands in $n$-heptane. 
For the asphaltene inhibitor B, the tensile and flexural bands were appeared at wavenumber of 3434 and $1601 \mathrm{~cm}^{-1}$, respectively. The acidic and polar nature of the asphaltene inhibitor $\mathrm{B}$ is due to the likely $\mathrm{N}-\mathrm{H}$ bands.

Figure 4 is the FT-IR spectrum for the asphaltene inhibitor C. In the wavenumber of 2926 and $2853 \mathrm{~cm}^{-1}$, there is $\mathrm{P}-\mathrm{CH}_{3}$ that acts as an acidic agent. Also, the binary $\mathrm{C}=\mathrm{O}$ band appears in the wavenumber of $1738 \mathrm{~cm}^{-1}$, which also arising from the polarity and acidity of $\mathrm{C}$ inhibitor.

\subsection{The effect of two $n$-paraffins on asphaltene precipitation}

In this work, $n$-Hexane and $n$-Heptane have been used to extract asphaltene in the crude oil. In each sample, crude oil was mixed with $n$-Hexane or $n$-Heptane for initial reflux and precipitation of asphaltene in crude oil $\left(\frac{n-\text { Hexaneor } n \text {-Heptane }}{\text { crudeoil }}=\frac{40}{1}\right)$. Other stages of asphaltene extraction were the same as the procedure, which was described in the previous section.

$0.0753 \mathrm{~g}$ of pure asphaltene was obtained when $n$-Hexane was used as asphaltene precipitant. Considering the crude oil density $(0.837 \mathrm{~g} / \mathrm{cc})$, the crude oil contained 3 wt.\% asphaltenes. However, there was $0.0141 \mathrm{~g}$ asphaltene in oil sample. Since heptane has more carbon atoms, it has a higher non-polar power. Therefore, $n$-Heptane can extract more asphaltene by interaction with non-polar region of asphaltene. Wiehe (2012) also stated that the solubility parameter of $n$-Heptane is higher than solubility parameter of $n$-Hexane, so that the amount of asphaltene precipitated by $n$-Heptane was higher than the amount of asphaltene precipitated by $n$-Hexane.

\subsection{Investigation the effect of inhibitors using IP-143 test}

The effect of asphaltene inhibitor on the asphaltene precipitation was calculated using equation (1):

\section{See Equation (1) bottom of the page}

$0.042 \mathrm{~g}$ of asphaltene was obtained by IP-143 method without using asphaltene inhibitor, which is considered as the basis for examining the effect of the adding different amounts of asphaltene inhibitors. However, by adding 500 ppm of asphaltene inhibitor A to crude oil, asphaltene precipitation was reduced to $0.025 \mathrm{~g}$. Based on equation (1), the decreasing of asphaltene precipitation was 40.47 wt.\% when $10000 \mathrm{ppm}$ of asphaltene inhibitor A was added to the crude oil, the conditions were quite different from the previous one. In this case, $0.46 \mathrm{~g}$ of asphaltene was obtained. Thus, the asphaltene precipitation has been increased 9 wt.\% alternatively, by adding 10000 ppm of asphaltene inhibitor A to the crude oil, the obtained results were unexpectable, and the amount of asphaltene precipitated was
Table 3. Effect of various quantities of A inhibitor on the amount of asphaltene extracted from the crude oil.

\begin{tabular}{lcc}
\hline $\begin{array}{l}\text { Amount of asphaltene } \\
\text { inhibitor A (ppm) }\end{array}$ & $\begin{array}{c}\text { Amount of } \\
\text { asphaltene } \\
\text { precipitated }\end{array}$ & $\begin{array}{c}\text { Asphaltene } \\
\text { reduction (\%) }\end{array}$ \\
\hline 0 & 0.042 & - \\
500 & 0.025 & 40.47 \\
1000 & 0.031 & 26.19 \\
1500 & 0.038 & 9.5 \\
2000 & 0.0407 & 3.09 \\
3000 & 0.0418 & 0.4 \\
10000 & 0.046 & -9.5 \\
\hline
\end{tabular}

Table 4. Effect of various quantities of B inhibitor on the amount of asphaltene extracted from the crude oil.

\begin{tabular}{lcc}
\hline $\begin{array}{l}\text { Amount of B } \\
\text { inhibitor (ppm) }\end{array}$ & $\begin{array}{c}\text { Amount of asphaltene } \\
\text { precipitated }\end{array}$ & $\begin{array}{c}\text { Asphaltene } \\
\text { reduction }(\%)\end{array}$ \\
\hline 0 & 0.042 & - \\
500 & 0.4224 & -0.57 \\
1000 & 0.044 & -4.76 \\
1500 & 0.0409 & 2.6 \\
2000 & 0.038 & 9.5 \\
3000 & 0.31 & 26.19 \\
10000 & 0.0286 & 31.9 \\
\hline
\end{tabular}

increased compared to the case without the asphaltene inhibitor. The results suggest that always adding asphaltene inhibitor does not necessarily reduce the amount of asphaltene precipitation. The effect of A inhibitor on the extracted asphaltene obtained by IP-143 method were presented in Table 3.

Mentioned tests have also been carried out on inhibitor B. The obtained results are shown in Table 4. As can be seen from this table, the increase in inhibitor B is associated with a decrease in the amount of asphaltene precipitated. When $3000 \mathrm{ppm}$ of asphaltene inhibitor B was added to crude oil, the amount of asphaltene extracted was 0.031 g. Based on equation (1), asphaltene precipitation was reduced 26.19 wt. \% but when 10000 ppm of asphaltene inhibitor B was added into the crude oil, this amount decrease to $0.0286 \mathrm{~g}$. Therefore, from the economic perspective, the concentration of $3000 \mathrm{ppm}$ from inhibitor B has the highest inhibitory effect (compared to the other concentration of asphaltene inhibitor B).

According to the results obtained from the IP-143 test, it can be seen that asphaltene inhibitor $\mathrm{A}$ has higher efficiency at same concentrations of A, B inhibitors.

$$
\text { Asphaltene reduction }(\%)=\frac{\text { Asphaltene content without inhibitor }- \text { Asphaltene content with inhibitor }}{\text { Asphaltene content without inhibitor }} \times 100 \text {. }
$$


Table 5. Amount of absorbance for mixture of synthetic oil $/ n \mathrm{C}_{7}$ with different concentration of inhibitors.

\begin{tabular}{lccccc}
\hline Amount of asphaltene inhibitor (ppm) & Non. & 500 & 1000 & 2000 & 3000 \\
\hline Absorbance in presence of inhibitor A & 0.534 & 1.03 & 0.925 & 0.855 & 0.88 \\
Absorbance in presence of inhibitor B & 0.534 & 0.87 & 0.895 & 1.38 & 1.6 \\
Absorbance in presence of inhibitor C & 0.534 & 0.97 & 0.87 & 0.875 & 0.87 \\
\hline
\end{tabular}

It is important to note that the IP-143 method was performed at a higher temperature than the spectrometry method, as well as the asphaltene precipitation time in the IP-143 method is greater than the time of asphaltene precipitation in spectrometry method. Therefore, a contradiction in the results obtained from these two methods was observed which indicates that asphaltene inhibitor $\mathrm{A}$ is more effective on the asphaltene precipitated in IP-143 method.

\subsection{Investigation of the effect of inhibitors using spectrometry method}

In order to investigate the effect of three different asphaltene inhibitors on the amount of asphaltene precipitation using spectrometry method, synthetic oil was prepared with concentration of $0.5 \mathrm{wt} . \%$ from asphaltene were mixed with ratio of $1: 1$ of oil: $n$-heptane ( $n$-Heptane 50 vol.\%). The results were shown in Table 5 .

The results obtained from spectrometry method (see Tab. 5) show that $\mathrm{A}$ and $\mathrm{C}$ inhibitors have the same inhibitory effect, although asphaltene inhibitor $\mathrm{A}$ at lower concentration is more effective which indicates that the asphaltene inhibitor A economically is better. As it is evident, asphaltene inhibitor B has a greater absorbance number than $\mathrm{A}$ and $\mathrm{C}$ inhibitors. It is noteworthy that the greater inhibitory power is available to inhibitor B at high concentrations of this inhibitor.

The higher inhibitory effect were occurred at 500, 3000 and $500 \mathrm{ppm}$ of $\mathrm{A}, \mathrm{B}$, and $\mathrm{C}$ inhibitors, respectively. The results obtained from the spectrometry method indicated that asphaltene inhibitor B has a higher inhibitory effect (at higher concentrations), however, from the economic point of view and in order to find an optimal concentration, asphaltene inhibitor $\mathrm{A}$ is the most acceptable one than $\mathrm{B}$ and $\mathrm{C}$ inhibitors. Therefore, the concentration of $500 \mathrm{ppm}$ of asphaltene inhibitors A considered as the optimal concentration (from the economic point of view), but in terms of inhibitory power, the asphaltene inhibitor B with a concentration of $3000 \mathrm{ppm}$ has the highest efficiency.

\subsection{Determination of the AOP using spectrometry method}

In this research, AOP was determined using spectrometry method. Further, various volumetric percentage of $n$-heptane were added to synthetic oil. Asphaltene precipitation was performed for $1.5 \mathrm{~h}$ at ambient conditions, then the mixture was centrifuged in a time of $15 \mathrm{~min}$ and at a rate of $3000 \mathrm{rpm}$, the absorbance number were determined

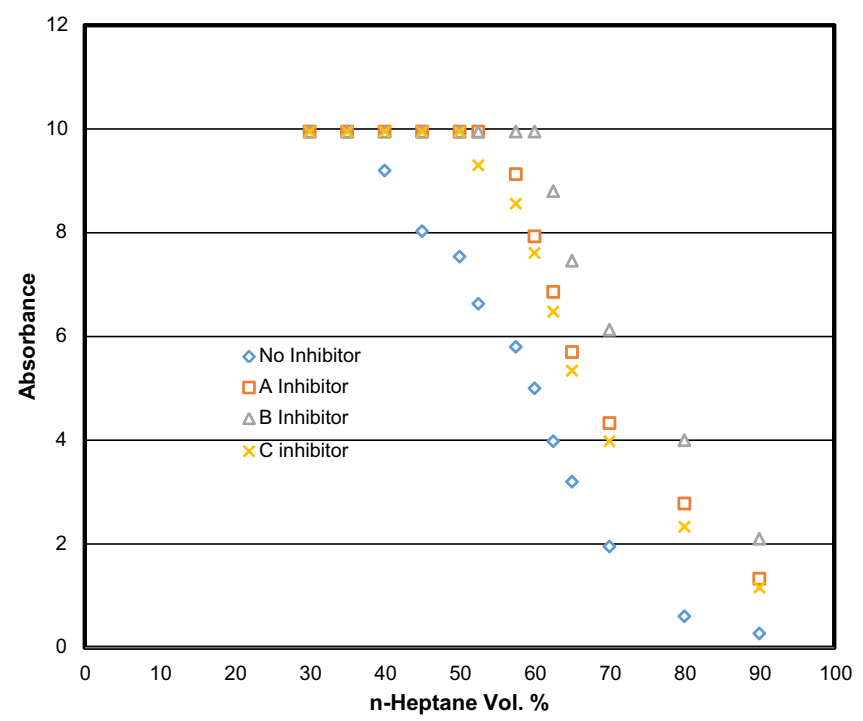

Fig. 5. Absorbance of synthetic oil as function of $n$-heptane vol. $\%$ in presence of different inhibitor.

at specified wavenumbers. The point at which the number of absorbance was defeated is known as AOP.

The AOP in the presence of optimal values from three different asphaltene inhibitors and without asphaltene inhibitors were shown in Figure 5.

As it is shown in this Table 5, without asphaltene inhibitor, the absorbance number reached a constant amount at $35 \mathrm{vol} . \%$ of $n$-heptane, which is introduced as AOP.

The absorbance number reached a constant amount in 52.5 vol. $\%$ of $n$-heptane, when the amount of $500 \mathrm{ppm}$ of inhibitor A was added to the mixture. As a result of adding optimal amounts of $\mathrm{B}$ and $\mathrm{C}$ inhibitors, AOPs were occurred at 60 and 50 vol.\% of $n$-heptane, respectively. It can be seen from Table 4 that at ambient temperature and pressure, in the presence of asphaltene inhibitor B, AOP was occurred at a larger volume of $n$-heptane, which indicates that this inhibitor is more effective in increasing the AOP. Due to the fact that the spectrometry method is carried out at ambient temperature and the IP-143 method is used at the boiling temperature of the mixture of normal paraffin and crude oil, the inhibitor performance varies in different temperature conditions. If the inhibitor is to be used in downstream industries where the temperature of the crude oil is nearer to the ambient temperature, the inhibitor A is better, if the inhibitor is to be injected at a higher operating temperature (inside the crude oil well), the inhibitor B have a higher efficiency. 


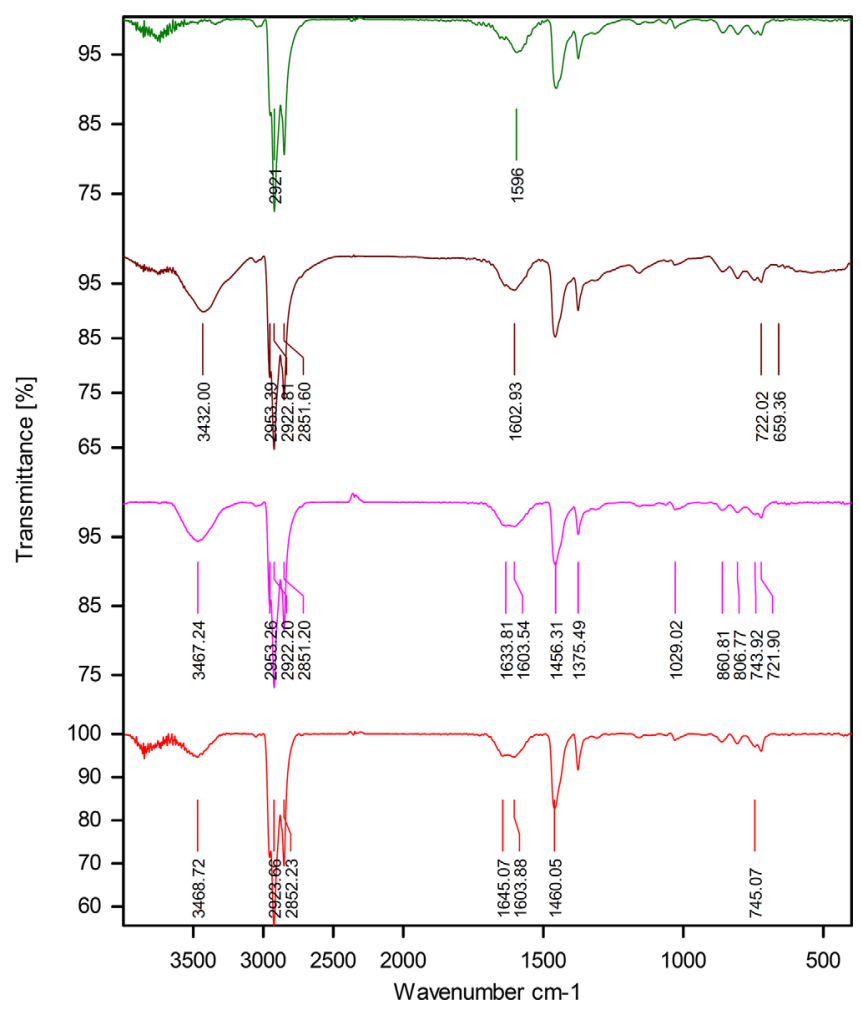

Fig. 6. The variation of the FT-IR spectrum for the asphaltene extracted in the presence of different amounts of the inhibitor A (the green, brown, purple and red spectra are related to concentration of $0,500,4200$ and $10000 \mathrm{ppm}$ of inhibitor A, respectively).

\subsection{FTIR analysis of various inhibitory effect}

FTIR spectrums for asphaltene were obtained from the IP-143 in the presence of different amount of acidic inhibitors were shown in Figure 6. As it can be seen from this figure, by adding asphaltene inhibitor A, the tensile and flexure bonding of $\mathrm{N}-\mathrm{H}$ were appeared with different intensities in the FTIR spectrum of asphaltene. As previously described, asphaltene is a dense aromatically ring with alkyl side chain and polarizing functional groups which is maintained in the crude oil solution by resin. Therefore, polar bands, such as tensile and flexure $\mathrm{N}-\mathrm{H}$ and $\mathrm{O}-\mathrm{H}$, can keep the asphaltene in the solution and prevent them to precipitate.

The pigments of the tensile and flexure were appeared at the wave number of 3467 and $1634 \mathrm{~cm}^{-1}$, respectively, when the amount of $500 \mathrm{ppm}$ of the asphaltene inhibitor A was added to the crude oil. The mentioned pigments were not exist in the asphaltene without chemical inhibitor. It can also be seen that the tensile and flexural of $\mathrm{N}-\mathrm{H}$ pigments, for $500 \mathrm{ppm}$ of asphaltene inhibitor added, has the highest severity. When $4200 \mathrm{ppm}$ of inhibitor A was added to the crude oil, the tensile and flexural pigments were appeared at 3468 and 1645 wavelengths, which are less than sample with $500 \mathrm{ppm}$ of asphaltene inhibitor. This difference in the intensity of the $\mathrm{N}-\mathrm{H}$ bands changes the amount

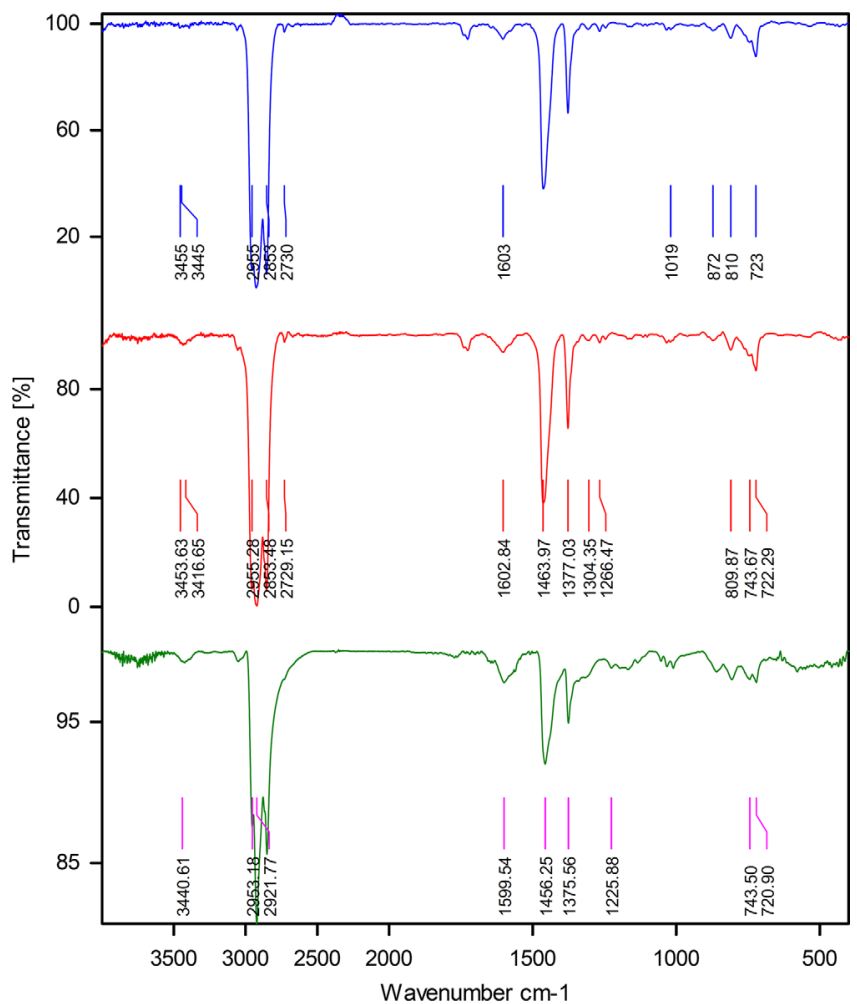

Fig. 7. The variation of the FT-IR spectrum for the asphaltene extracted in the presence of different amounts of the inhibitor B (the blue, red and green spectra are related to concentration of 1000, 2000 and 3000 ppm of inhibitor B, respectively).

of asphaltene obtained from the IP-143 method. By adding $10000 \mathrm{ppm}$ of the asphaltene inhibitor A, the FTIR spectrum was different from the other samples. As shown in Figure 6 , the picks of $\mathrm{N}-\mathrm{H}$ flexure in $3468 \mathrm{~cm}^{-1}$ wavelength is considerably reduced, which could be one of the main reasons for the increased of asphaltene extracted from the crude oil by adding $10000 \mathrm{ppm}$ of asphaltene inhibitor A. The pigtails of the $\mathrm{C}=\mathrm{C}$ double band was also appeared at the $1400 \mathrm{~cm}^{-1}$ wave number. The $\mathrm{C}=\mathrm{C}$ dual band is a strong non-polar band that can be linked to a non-polarnon-polar bond with asphaltene. Hence, $n$-paraffin can be more easily linked to non-polar part of the asphaltene, which were potentiated by adding up to $10000 \mathrm{ppm}$ of asphaltene inhibitor. Hence, asphaltene precipitation was increased.

The FT-IR spectrum for the extracted asphaltene from the crude oil for the cases in which the amount of 1000 , 2000 and $3000 \mathrm{ppm}$ of asphaltene inhibitor B were added to the crude oil, respectively, are shown in Figure 7. In this figure, new pigments appear in the FTIR spectrum of the extracted asphaltene for the case that $3000 \mathrm{ppm}$ of asphaltene inhibitor B (the concentration, which shows the highest inhibitory effect for asphaltene inhibitor B), were added to crude oil. In the wavenumber of $3051 \mathrm{~cm}^{-1}$ a double carbon bonding was appeared, causing a greater amount of asphaltene precipitation, while in wavenumber of 
$3440 \mathrm{~cm}^{-1}$, a slightly tensile $\mathrm{N}-\mathrm{H}$ was formed, which reduces the asphaltene precipitation. In the wavenumber of 2953-2921 cm $\mathrm{cm}^{-1}$, the bands belong the aliphatic group $\left(\mathrm{CH}_{3}\right)$, which increases the non-polar behavior and consequently increases the asphaltene precipitation. In the wavenumber of $1136 \mathrm{~cm}^{-1}$, an acidic $\mathrm{C}-\mathrm{O}$ bond was also appeared. This $\mathrm{C}-\mathrm{O}$ bond reduces the amount of precipitated asphaltene and increases the absorbance number of UV test. In general, by adding $3000 \mathrm{ppm}$ of asphaltene inhibitor $\mathrm{B}$, due to the high contrast between polar and non-polar bonds, the percentage of the reduced asphaltene was not as considerable as expected. Nevertheless, due to polar bonds being overcome by non-polar bonds, adding this amount from asphaltene inhibitor B showed a positive effect on asphaltene precipitation.

According to Figure 7, by adding 1000 and 2000 ppm of asphaltene inhibitor $\mathrm{B}$, the intensity of the $\mathrm{N}-\mathrm{H}$ and $\mathrm{C}-\mathrm{O}$ bands for the extracted asphaltene decreases, which causes a decrease in the asphaltene polarization, therefore, the extracted asphaltene was increased rather than the case that $3000 \mathrm{ppm}$ of asphaltene inhibitor B was added to the crude oil.

As a general conclusion of the results of the FTIR spectrums, at high temperatures, asphaltene inhibitor A forms stronger polar bands than asphaltene inhibitor B.

Asphaltene acts like Lewis base, therefore it interacts well with the inhibitor, which plays as a Lewis acid. Considering that $\mathrm{pH}$ for $\mathrm{A}, \mathrm{B}$ and $\mathrm{C}$ asphaltene inhibitors are $3.8,2.8$ and 5.3 respectively, it can be concluded that the acidic properties of these inhibitors result in the stability of asphaltene in crude oil. Also, because asphaltene acts as a strong receiver of a hydrous band and a poor supply of hydrous bands, the transfer of the hydroxide band from acidic inhibitors to asphaltene causes its stabilization in crude oil.

\section{Conclusion}

In this research, the effect of three different asphaltene inhibitor on reduction of asphaltene precipitation by two different methods such as IP143 and spectrometry methods have been investigated. AOP was also determined by spectrometry method. The following conclusions were obtained from this research, which confirms that Asphaltenes would act as Lewis base: The inhibitors that have acidic and polar portions, play a role in the formation of resin as a result of the formation of bond with the polar regions of asphaltene, which reduces the asphaltene deposited in the crude oil due to the presence of normal paraffin. In addition to reducing the amount of asphaltene sedimentation, chemical inhibitors also cause the AOP to be dropped. The experimental results show that temperature condition is a key factor on the performance of different inhibitors on decreasing asphaltene precipitation.

Acknowledgments. The authors would like to thank Ilam University and Iranian Central Oil Company for the financial support of this work. Also, thank co-workers and technical staff in the chemical engineering department.

\section{References}

Afra S., Nasr-El-Din H.A., Socci D., Cui Z. (2018) Green phenolic amphiphile as a viscosity modifier and asphaltenes dispersant for heavy and extra-heavy oil, Fuel 220, 481-489. doi: 10.1016/j.fuel.2018.01.111.

Ahmadi Y., Aminshahidy B. (2018) Effects of hydrophobic CaO and $\mathrm{SiO}_{2}$ nanoparticles on Asphaltene Precipitation Envelope (APE): An experimental and modeling approach, Oil Gas Sci. Technol. - Rev. IFP Energies nouvelles 73, 56.

Al-Sahhaf T.A., Fahim M.A., Elkilani A.S. (2002) Retardation of asphaltene precipitation by addition of toluene, resins, deasphalted oil and surfactants, Fluid Phase Equilib. 194-197, 1045-1057. doi: 10.1016/S0378-3812(01)00702-6.

Bahman J., Sharifi K., Nasiri M., Haghighi Asl M. (2018) Development of a Log-Log scaling law approach for prediction of asphaltene precipitation from crude oil by n-alkane titration, J. Pet. Sci. Eng. 160, 393-400. doi: 10.1016/j.petrol.2017.10.078.

Berenblyum R., Shchipanov A., Surguchev L., Kollbotn L. (2011) $\mathrm{CO}^{2}$ EOR and storage-lessons learned from several case studies, IOR 2011 - 16th European Symposium on Improved Oil Recovery.

Chávez-Miyauchi T.E., Zamudio-Rivera L.S., Barba-López V., Buenrostro-Gonzalez E., Martínez-Magadán J.M. (2013) $\mathrm{N}$-aryl amino-alcohols as stabilizers of asphaltenes, Fuel 110, 302-309. doi: 10.1016/j.fuel.2012.10.044.

Choi S., Byun D.H., Lee K., Kim J.-D., Nho N.S. (2016) Asphaltene precipitation with partially oxidized asphaltene from water/heavy crude oil emulsion, J. Pet. Sci. Eng. 146, 21-29. doi: 10.1016/j.petrol.2016.04.012.

David Ting P., Hirasaki G.J., Chapman W.G. (2013) Modeling of asphaltene phase behavior with the SAFT equation of state, Pet. Sci. Technol. 21, 647-661. doi: 10.1081/LFT-120018544.

Dehaghani Y.H., Assareh M., Feyzi F. (2018) Asphaltene precipitation modeling with $\mathrm{PR}$ and PC-SAFT equations of state based on normal alkanes titration data in a Multisolid approach, Fluid Phase Equilib. 470, 212-220. doi: 10.1016/j. fluid.2017.11.012.

Doryani H., Malayeri M.R., Riazi M. (2016) Visualization of asphaltene precipitation and deposition in a uniformly patterned glass micromodel, Fuel 182, 613-622. doi: 10.1016/ j.fuel.2016.06.004.

Doryani H., Malayeri M.R., Riazi M. (2018) Precipitation and deposition of asphaltene in porous media: Impact of various connate water types, J. Mol. Liq. 258, 124-132. doi: 10.1016/ j.molliq.2018.02.124.

Ebrahimi M., Mousavi-Dehghani S.A., Dabir B., Shahrabadi A. (2016) The effect of aromatic solvents on the onset and amount of asphaltene precipitation at reservoir conditions: Experimental and modeling studies, J. Mol. Liq. 223, 119-127. doi: 10.1016/j.molliq.2016.07.010.

Escobedo J., Mansoori G.A. (1995) Viscometric determination of the onset of asphaltene flocculation: A novel method, SPE Prod. Facil. 10, 115-118. Document ID: SPE-28018-PA. doi: 10.2118/28018-pa.

Gharbi K., Benyounes K., Khodja M. (2017) Removal and prevention of asphaltene deposition during oil production: A literature review, J. Pet. Sci. Eng. 158, 351-360. doi: $10.1016 /$ j.petrol.2017.08.062.

Ghloum E.F., Al-Qahtani M., Al-Rashid A. (2010) Effect of inhibitors on asphaltene precipitation for Marrat Kuwaiti reservoirs, J. Pet. Sci. Eng. 70, 99-106. doi: 10.1016/j. petrol.2009.10.003. 
Gonzalez K., Nasrabadi H., Barrufet M. (2017) Modeling asphaltene precipitation in a compositional reservoir simulator using three-phase equilibrium, J. Pet. Sci. Eng. 154, 602-611. doi: $10.1016 /$ j.petrol.2016.09.010.

Hammami A., Phelps C.H., Monger-McClure T., Little T.M. (2000) Asphaltene precipitation from live oils: An experimental investigation of onset conditions and reversibility, Energy Fuels 14, 14-18. doi: 10.1021/ef990104z.

Honse S.O., Ferreira S.R., Mansur C., Lucas E.F., González G. (2012) Separation and characterization of asphaltenic subfractions, Quím Nova 35, 1991-1994. doi: 10.1590/S010040422012001000019.

Hu Y.-F., Guo T.-M. (2001) Effect of temperature and molecular weight of n-alkane precipitants on asphaltene precipitation, Fluid Phase Equilib. 192, 13-25. doi: 10.1016/S0378-3812(01) 00619-7.

Imanbayev Y., Ongarbayev Y., Tileuberdi Y., Krivtsov E., Golovko A., Mansurov Z. (2017) High temperature transformation of tar-asphaltene components of oil sand bitumen, $J$. Serb. Chem. Soc. 82, 1063-1073.

Javanbakht G., Sedghi M., Welch W.R.W., Goual L., Hoepfner M.P. (2018) Molecular polydispersity improves prediction of asphaltene aggregation, J. Mol. Liq. 256, 382-394. doi: 10.1016/j.molliq.2018.02.051.

Karambeigi M.A., Nikazar M., Kharrat R. (2016) Experimental evaluation of asphaltene inhibitors selection for standard and reservoir conditions, J. Pet. Sci. Eng. 137, 74-86. doi: 10.1016/j.petrol.2015.11.013.

Loureiro T.S., Palermo L.C.M., Spinelli L.S. (2015) Influence of precipitation conditions (n-heptane or carbon dioxide gas) on the performance of asphaltene stabilizers, J. Pet. Sci. Eng. 127, 109-114. doi: 10.1016/j.petrol.2015.01.023.

Lu G-W, Li Y-F, Song H, Yu Y-H, Wang C-I (2008) Micromechanism of petroleum asphaltene aggregation, Pet. Explor. Dev. 35, 67-72. doi: 10.1016/S1876-3804(08)60010-5.

Mao J., Liu J., Wang H., Yang X., Zhang Z., Yang B., Zhao J. (2017) Novel terpolymers as viscosity reducing agent for Tahe super heavy oil RSC, Advances 7, 19257-19261.

Melendez-Alvarez A.A., Garcia-Bermudes M., Tavakkoli M., Doherty R.H., Meng S., Abdallah D.S., Vargas F.M. (2016) On the evaluation of the performance of asphaltene dispersants, Fuel 179, 210-220. doi: 10.1016/j.fuel.2016.03.056.

Mena-Cervantes V.Y., Hernández-Altamirano R., BuenrostroGonzález E., Beltrán H.I., Zamudio-Rivera L.S. (2013) Development of oxazolidines derived from polyisobutylene succinimides as multifunctional stabilizers of asphaltenes in oil industry, Fuel 110, 293-301. doi: 10.1016/j.fuel.2012.12.071.

Mousavi-Dehghani S.A., Riazi M.R., Vafaie-Sefti M., Mansoori G.A. (2004) An analysis of methods for determination of onsets of asphaltene phase separations, J. Pet. Sci. Eng. 42, 145-156. doi: 10.1016/j.petrol.2003.12.007.

Nasralla R.A., Mahani H., van der Linde H.A., Marcelis F.H., Masalmeh S.K., Sergienko E., Brussee N.J., Pieterse S.G., Basu S. (2018) Low salinity waterflooding for a carbonate reservoir: Experimental evaluation and numerical interpretation, J. Pet. Sci. Eng. 164, 640-654. doi: 10.1016/j.petrol.2018.01.028.

Ovalles C., Rogel E., Morazan H., Moir M.E. (2016) Synthesis, characterization, and mechanism of asphaltene inhibition of phosphopropoxylated asphaltenes, Fuel 180, 20-26. doi: 10.1016/j.fuel.2016.03.084.

Permanyer A., Douifi L., Lahcini A., Lamontagne J., Kister J. (2002) FTIR and SUVF spectroscopy applied to reservoir compartmentalization: A comparative study with gas chromatography fingerprints results, Fuel 81, 861-866.

Ramirez M.I., Arevalo A.P., Sotomayor S., Bailon-Moscoso N. (2017) Contamination by oil crude extraction - Refinement and their effects on human health, Environ. Pollut. 231, 415-425.

Rogel E., Moir M. (2017) Effect of precipitation time and solvent power on asphaltene characteristics, Fuel 208, 271-280. doi: 10.1016/j.fuel.2017.06.116.

Saeedi Dehaghani A.H., Badizad M.H. (2017) Inhibiting asphaltene precipitation from Iranian crude oil using various dispersants: Experimental investigation through viscometry and thermodynamic modelling, Fluid Phase Equilib. 442, 104-118. doi: 10.1016/j.fluid.2017.03.020.

Sayyad Amin J., Nikkhah S., Zendehboudi S. (2017) A new experimental and modeling strategy to determine asphaltene precipitation in crude oil, Chem. Eng. Res. Des. 128, 162-173. doi: 10.1016/j.cherd.2017.09.035.

Shojaati F., Mousavi S.H., Riazi M., Torabi F., Osat M. (2017) Investigating the effect of salinity on the behavior of asphaltene precipitation in the presence of emulsified water, Ind. Eng. Chem. Res. 56, 14362-14368. doi: 10.1021/acs.iecr.7b03331.

Simakov S.K., Kouchi A., Melnik N.N., Scribano V., Kimura Y., Hama T., Suzuki N., Saito H., Yoshizawa T. (2015) Nanodiamond finding in the hyblean shallow mantle xenoliths, Sci. Rep. 5, 10765.

Smith D.F., Klein G.C., Yen A.T., Squicciarini M.P., Rodgers R.P., Marshall A.G. (2008) Crude oil polar chemical composition derived from FT-ICR mass spectrometry accounts for asphaltene inhibitor specificity, Energy Fuels 22, 3112-3117.

Tirjoo A., Bayati B., Rezaei H., Rahmati M. (2019a) Molecular dynamics simulation of the effect of ions in water on the asphaltene aggregation, J. Mol. Liq. 277, 40-48.

Tirjoo A., Bayati B., Rezaei H., Rahmati M. (2019b) Molecular dynamics simulations of asphaltene aggregation under different conditions, J. Pet. Sci. Eng. 177, 392-402.

Wang J.X., Buckley J.S. (2001) A two-component solubility model of the onset of asphaltene flocculation in crude oils, Energy Fuels 15, 1004-1012. doi: 10.1021/ef0100121.

Wiehe I.A. (2012) Asphaltene solubility and fluid compatibility, Energy Fuels 26, 4004-4016.

Wiehe I.A., Yarranton H.W., Akbarzadeh K., Rahimi P.M., Teclemariam A. (2005) The paradox of asphaltene precipitation with normal paraffins, Energy Fuels 19, 1261-1267. doi: 10.1021/ef0496956. 